\title{
Biological control of fusarium root rot of Indian mulberry (Morinda officinalis How.) with consortia of agriculturally important microorganisms in Viet Nam
}

\author{
Duong Thi Nguyen ${ }^{1}$, Nguyen Chi Hieu' ${ }^{1}$ Nguyen Viet Hung ${ }^{1}$, Hoang Thi Bich Thao ${ }^{1}$, Chetan Keswani²,
} Pham Van Toan ${ }^{3}$ and Trinh Xuan Hoat ${ }^{4^{*}}$ (1)

\begin{abstract}
Background: Fusarium root rot disease in Indian mulberry (Morinda officinalis How.) (FRRBK), caused by Fusarium proliferatum (FP), is widespread and responsible for serious economic losses in Viet Nam. The efficacy of a new bioproduct named MICROTECH-1(NL) is compared with other commercial products for suppression of FP under in vitro, pot, nursery as well as in the field conditions.

Results: In in vitro antagonistic assay, MICROTECH-1(NL) significantly inhibited the mycelial growth of FP (72.38\%). Under pot conditions, the efficacy of all the bio-products was significantly higher when applied prior to pathogen inoculation. The disease severity of treatments with double application of MICROTECH-1(NL) (applied both in the nursery and in the pot soil) was only $15.56 \%$, significantly lower than control (80\%). Thus, the application of MICROTECH-1(NL) significantly reduced the incidence of FP and markedly increased the number of plant beneficial bacteria and actinobacteria in rhizoplane of $M$. officinalis compared to untreated control. In the field conditions, double application of MICROTECH-1(NL) (both in the nursery and in the field soils) significantly decreased disease severity in comparison to single application in nursery or field.
\end{abstract}

Conclusion: The most effective treatment was double application of MICROTECH-1(NL), which significantly reduced the disease severity and FP population in roots of $M$. officinalis and increased the population of plant beneficial microbes.

Keywords: Ba kich, Biological control, Fusarium proliferatum, Morinda officinalis

\section{Background}

In Viet Nam, Indian mulberry (Morinda officinalis How.) is locally known as Ba kich and is widely grown in many mountainous provinces in the north of Viet Nam including Thai Nguyen, Quang Ninh, Ha Tay, Bac Giang, Bac Ninh, Lang Son, Tuyen Quang, Cao Bang, Bac Kan, Lao Cai, Yen Bai, Phu Tho, Lai Chau, Son La, Hoa Binh, Thanh Hoa, and Nghe An. Roots of Ba kich are used for

\footnotetext{
*Correspondence: trinhxuanhoatppri@gmail.com

${ }^{4}$ Plant Protection Research Institute of Viet Nam, Duc Thang, Bac Tu Liem District, Ha Noi City, Viet Nam

Full list of author information is available at the end of the article
}

medicinal purposes in traditional medicine as it is rich in various medicinal compounds [1].

Fusarium root rot of Ba kich (FRRBK) is a widespread soil-borne disease, which can cause serious damage and huge economic losses to Ba kich production in Viet Nam. Fusarium proliferatum (FP) has been identified as the causal pathogen of FRRBK [1]. It was shown that long periods of continuous cropping of Ba kich with high planting density and intensified soil acidification from chemical $\mathrm{N}$ fertilization and less use of organic manures may change in the soil microbiome, subsequently leading to disease outbreak [1]. Since Ba kich is directly used for human consumption, overuse of chemical fertilizers and 
chemical pesticides may be a potential threat for both human and environmental health. Thus, application of antagonistic microorganisms is a promising eco-friendly alternative for the efficient management of FRRBK.

Antagonistic microorganisms play an important role in management of different plant diseases $[2,3]$ and enhance plant growth [4] via different mechanisms. It was showed that soaking banana suckers in the suspension of Pseudomonas fluorescens before planting significantly decreased the wilt incidence of fusarium wilt of banana caused by F. oxysporum f. sp. cubense [5]. Bacillus spp. were used for suppressing tomato fusarium crown and root rot disease [6], significantly inhibited growth of $F$. verticillioides and fumonisin B1 accumulation, reduced rhizoplane and endorhizosphere colonization of the pathogen [7], suppressed growth of $F$. oxysporum in the rhizosphere of cucumber, and protected the host plant from the pathogen [8]. The fluorescent pseudomonads are potential beneficial agents of various soil-borne diseases [9-11] via different mechanisms [12], which promote plant growth [2]. They also produce antimicrobial metabolites [13], trigger induced systemic resistance (ISR) in plants leading to protection against a broad spectrum of diseases [13, 14].

Streptomycetes, are antibiotic producers [15], were reported to significantly inhibit the growth of Fusarium spp. $[16,17]$ and reduce disease incidence and disease severity of different Fusarium diseases [16, 18, 19]. Lactic acid bacteria also produce various compounds such as organic acids, diacetyl, hydrogen peroxides, bacteriocins, and bactericidal proteins [20], reduce the soil $\mathrm{pH}$, and create unfavorable environmental condition to soil-borne pathogens [21], and were used to control Fusarium diseases caused by F. nygamai and E. amylovora [22-24].

It was reported that photosynthetic bacteria were widely used to promote plant growth and improve plant quality [25]. Various compounds produced by Rhodopseudomonas palustris induced systemic resistance in plants and possessed ISR-inducing properties [26, 27]. In the field conditions, foliar spray of $R$. palustris GJ-22 suspension protected tobacco plants against tobacco mosaic virus (TMV) by colonizing the phyllosphere and inducing resistance against TMV [27]. Saccharomyces cerevisiae acts as a natural stimulator [28], plays an essential role in cell division and cell enlargement due to its cytokinin content [29] and acts as a biocontrol agent of soil-borne fungal pathogen $F$. oxysporum in sugar beet seedlings [30]. Azotobacter sp., a free living $\mathrm{N}_{2}$ fixing bacterium, synthesizes and secretes considerable amounts of biologically active substances promoting root growth and improving nutrient uptake by the plants [31]. Azotobacter isolate AZT-R7 acted as a potential biocontrol agent against fusarium wilt of chilli in India [32].
The present study was undertaken to investigate our newly developed bio-product named MICROTECH1(NL) that composed from P. fluorescens, B. subtilis, Streptomyces spp., L. casei, R. palustris, S. cerevisiae, Azotobacter sp. against FP and FRRBK in in vitro, nursery, pot, and field conditions, and compared to other commercial bio-products available in Viet Nam.

\section{Materials and methods}

\section{Inoculum preparation}

Three isolates of FP designated as BKVN, BKDT, and BKPL were used in this study. They were grown on PDA for 3 days in the dark at $25{ }^{\circ} \mathrm{C}$. Mycelial disks $(5 \mathrm{~mm}$ diameter) were transferred to $100 \mathrm{~mL}$ potato dextrose broth in a $500-\mathrm{mL}$ flask and incubated for 7 days at $25^{\circ} \mathrm{C}$ with shaking at $120 \mathrm{rpm}$. The fungal suspensions was harvested and diluted with sterile distilled water. It was adjusted to $5 \times 10^{6} \mathrm{cfu} \mathrm{mL}^{-1}$ and used as inocula for further experiments [1].

\section{Plants and bio-products}

Ba kich seedlings were grown in small plastic pots $(5 \times 15 \times 5 \mathrm{~cm})$ in the nursery for about 1 year before planting in the field. Seven commercially available bioproducts were applied to evaluate their effects on the development of FP and FRRBK. They were (1) Actino Vate (S. lydicus WYEC $1081 \times 10^{7}$ CFU/g, Golden Rice Hau Giang Co. Ltd.), (2) Bionite (B. subtilis $10^{9} \mathrm{CFU} / \mathrm{g}$, Bio-AgriTech Co. Ltd.), (3) Ketomium (C. cupreum $1.5 \times 10^{6} \mathrm{CFU} / \mathrm{g}$, Nam Bac Co. Ltd.), (4) BIMA (Trichoderma sp. $5 \times 10^{6} \mathrm{CFU} / \mathrm{g}$, SaiGon Pesticide Co. Ltd.), (5) TRICHO (consortia of Trichoderma spp., B. subtilis, Pseudomonas sp., and Streptomyces spp., Dien Trang Co. Ltd.), (6) SH-BV1 (consortia of T. viride, B. subtilis, B. oisengihumi, A. beijerinckii, S. owasiensis, and M. anisopliae, Plant Protection Research Institute (PPRI), Viet Nam), and (7) MICROTECH-1(NL) (consortia of P. fluorescens, B. subtilis, Streptomyces spp., L. casei, R. palustris, S. cerevisiae, Azotobacter sp., PPRI, Viet Nam). Among them, SH-BV1 and MICROTECH-1(NL) are new bio-products developed by PPRI. According to the recommendation from the manufacturers, the bio-products were diluted at the following rates: Actino Vate $(0.25 \mathrm{~g} / \mathrm{L})$, Bionite $(0.3 \mathrm{~g} / \mathrm{L})$, Ketomium $(1 \mathrm{~g} / \mathrm{L})$, BIMA ( $1 \mathrm{~g} / \mathrm{L})$, TRICHO $(2.5 \mathrm{~g} / \mathrm{L})$, SH-BV1 (3 g/L), and MICROTECH$1(\mathrm{NL})(0.1 \% \mathrm{v} / \mathrm{v})$. For the pot and soil experiments, all the diluted bio-products were applied as drenches at the rate of $50 \mathrm{~mL}$ per plant.

\section{Effect of MICROTECH-1(NL) on mycelial growth of $F$. proliferatum}

Petri plate experiments were carried out to investigate the antagonistic effect of MICROTECH-1(NL) on the 
mycelial growth of three isolates of FP (BKVN, BKDT, and BKPL). Each experiment had total of eight treatments arranged in completely randomized design with five petri plates per treatment as five replications. The eight treatments were untreated-control and the seven bio-products applied to $100 \mathrm{~mL}$ sterilized PDA medium at $60{ }^{\circ} \mathrm{C}$ before being divided equally into five petri plates (as five replications) at the following rates: Actino Vate at $0.25 \mathrm{~g} / \mathrm{L}$, Bionite at $0.3 \mathrm{~g} / \mathrm{L}$, Ketomium at $1 \mathrm{~g} / \mathrm{L}$, BIMA at $1 \mathrm{~g} / \mathrm{L}$, TRICHO at $2.5 \mathrm{~g} / \mathrm{L}, \mathrm{SH}-\mathrm{BV} 1$ at $3 \mathrm{~g} / \mathrm{L}$, and MICROTECH-1(NL) at $1 \%(\mathrm{v} / \mathrm{v})$. The control plates were prepared by replacing the bio-products with the same amount of sterile distilled water. Colony growth in diameter of BKVN, BKDT, and BKP isolates was measured and recorded on the 7th day after treatment. The inhibition percentage (\%) of each bio-product on mycelial growth of each FP isolate was determined at the 7th day of incubation following formula $(1-\mathrm{Cn} / \mathrm{Co}) \times 100$, where $\mathrm{Cn}$ is the average diameter of $\mathrm{FP}$ colony in treatment plates, and Co is the average diameter of FP colony in control plates.

\section{Effect of MICROTECH-1(NL) on disease severity of FRRBK in pot condition}

Three pot experiments were carried out to investigate the effects of MICROTECH-1(NL) and other bio-products on disease severity of FRRBK using three application approaches: (1) In the first experiment, all the bio-products were drenched in the soil 1 week before pathogen inoculation, (2) In the second experiment, all the bio-products and the pathogen spores were applied simultaneously, and (3) In the third experiment, all the bio-products were drenched to the pots 1 week after pathogen inoculation. Each experiment had three replications, eight treatments (untreated control and the seven bio-products applied at the rates mentioned above), arranged in completely randomized design with thirty (30) pots per treatment. One eight-leaf stage (about 1 year old) seedling was transplanted to each pot $(20 \times 40 \times 20 \mathrm{~cm})$ containing FP-infested soils.

The disease severity was recorded on $0-3$ visual scales, in which 0 was no symptoms; 1 was light yellowing of leaves, light or moderate rot on taproot, secondary roots, and crown rot; 2 was moderate or severe yellowing of leaves with or without wilting, stunting, severe rot on taproot, secondary roots, crown rot with or without hypocotyls rot, and vascular discoloration in the stem; and 3 was dead plants. The disease severity (\%) was determined using the following formula:

$$
\begin{aligned}
& \text { Disease severity }(\%) \\
& \qquad=\frac{\left(\sum \text { scale } \times \text { number of plants infected }\right)}{(\text { Highest scale } \times \text { total number of plants })} * 100
\end{aligned}
$$

Effect of MICROTECH-1(NL) on microorganism in the soil FP-infested soil was obtained from the field in Vo Nhai district of Thai Nguyen province in which Ba kich had been previously planted and seriously infested with fusarium root rot disease. The spore concentration of FP in this soil was assessed by PDA plate method and resulted of $2.3 \times 10^{5} \mathrm{cfu} \mathrm{g}^{-1}$ soil.

Treatments were applied to both nursery and pot soils. In the nursery, soils were treated with either SH-BV1 (SHn), or MICROTECH-1(NL) (MIn), or none of SH-BV1 and MICROTECH-1(NL) (Cn) as untreated controls. In the pot, soils were treated with $1 \%(\mathrm{v} / \mathrm{v})$ MICROTECH-1(NL) (MIp), 1\% (w/w) SH-BV1, or none of SH-BV1 and MICROTECH-1(NL) (Cp). Combination of two phases treatments resulted in eight treatments that were: (1) SHn + Cp: SH-BV1treated nursery soil + untreated pot soils; (2) Cn + SHp: untreated nursery soils + SH-BV1-treated pot soils; (3) SHn + SHp: SH-BV1-treated nursery and pot soils; (4) MIn + Cp: MICROTECH-1(NL)-treated nursery soils, untreated pot soils; (5) Cn + MIp: untreated nursery soils, MICROTECH-1(NL)-treated pot soils; (6) MIn + MIp: MICROTECH-1(NL)-treated nursery and pot soils; (7) SHnp + MInp: SH-BV1-treated nursery and pot soils, MICROTECH-1(NL)-treated nursery and pot soils; and (8) $\mathrm{Cn}+\mathrm{Cp}$ : untreated nursery and pot soils. All amendments were mixed well with the soil before putting into nursery or pots. To ensure sufficiently high density of FP population, all pot soils were inoculated with the spores of FP isolate at $10^{5}$ $\mathrm{cfu} \mathrm{g}^{-1}$ soil before putting into pots. Experiment had three replications with randomize design and 50 pots per treatment.

Two months after transplanting, numbers of diseased and healthy plants were recorded, and disease severity was calculated. Five plants (with maximum disease symptoms in the aerial parts) in each replication were sampled. Roots were taken from the pots and carefully shaken by hand to remove soil; these soil samples represented rhizosphere soils; soil that still adhered to roots, and the root themselves, were considered as rhizoplane samples. The microorganisms were enumerated by the standard tenfold dilution method. FP was isolated from roots of Ba kich, rhizoplane, and rhizosphere soils using Komada selective medium (KSM) $\left(1 \mathrm{~g} \mathrm{~K}_{2} \mathrm{HPO}_{4}, 0.5 \mathrm{~g} \mathrm{KCl}\right.$, $0.5 \mathrm{~g} \mathrm{MgSO}_{4} \cdot 7 \mathrm{H}_{2} \mathrm{O}, 0.01 \mathrm{~g} \mathrm{Fe}-\mathrm{Na}-\mathrm{EDTA}, 2 \mathrm{~g} \mathrm{~L}$-asparagin, $20 \mathrm{~g}$ D-galactose, and distilled water up to $1 \mathrm{~L}, \mathrm{pH}$ 7.0). Total bacteria and actinobacteria were isolated from rhizoplane and rhizosphere soils using Gauze's medium (20 g soluble starch, $1 \mathrm{~g} \mathrm{KNO}_{3}, 0.5 \mathrm{~g} \mathrm{NaCl}, 0.5 \mathrm{~g} \mathrm{~K}_{2} \mathrm{HPO}_{4}$, $0.5 \mathrm{~g} \mathrm{MgSO}_{4}, 0.01 \mathrm{~g} \mathrm{FeSO}_{4}, 20 \mathrm{~g}$ agar, and distilled water up to $1 \mathrm{~L}, \mathrm{pH}$ 7.2). Total fungi were isolated from rhizoplane and rhizosphere soils using Martin medium (10 g 
glucose, 5 g peptone, $1 \mathrm{~g} \mathrm{KH}_{2} \mathrm{PO}_{4}, 0.5 \mathrm{~g} \mathrm{MgSO}_{4}, 30 \mathrm{~g}$ Rose Bengal, $0.03 \mathrm{~g}$ streptomycin, and distilled water up to $1 \mathrm{~L}$ ). The FP populations, bacterial and fungal isolation, and enumeration from soil and root samples were carried out as described previously [33].

\section{Effect of MICROTECH-1(NL) on disease severity in the field condition}

Field experiments for effective management of FRRBK were carried out independently in Vo Nhai, Dai Tu, and Phu Luong districts, Thai Nguyen province by applying two bio-products SH-BV1 and MICROTECH-1(NL). Treatments were applied to both nursery and field soil. In the nursery, soils were treated with either SH-BV1 (SHn), or MICROTECH-1(NL) (MIn), or none of SH-BV1 and MICROTECH-1(NL) (Cn) as untreated controls. In the field, soils were treated with $1 \%(\mathrm{v} / \mathrm{v})$ MICROTECH1(NL) (MIf), 1\% (w/w) SH-BV1 (SHf), or none of SH-BV1 and MICROTECH-1(NL) (Cf). Combination of two phases treatments resulted in ten treatments that were: (1) SHn + Cf: SH-BV1-treated nursery soil, untreated field soil; (2) Cn + SHf: untreated nursery soil, SH-BV1treated field soil; (3) SHn + SHf: SH-BV1-treated nursery and field soil; (4) MIn + Cf: MICROTECH-1(NL)-treated nursery soil, untreated field soil; (5) Cn + MIf: untreated nursery soil, MICROTECH-1(NL)-treated field soil; (6) MIn + MIf: MICROTECH-1(NL)-treated nursery and field soils; (7) SHn + MIf: SH-BV1-treated nursery soil, MICROTECH-1(NL)-treated field soil; (8) MIn + SHf: MICROTECH-1(NL)-treated nursery soil, SH-BV1-treated field soil; (9) SHnf+MInf: SH-BV1 and MICROTECH-1(NL)-treated nursery and field soils; and (10) $\mathrm{Cn}+\mathrm{Cf}$ : nursery and field soils were not treated as control. The application rate of SH-BV1 and MICROTECH-1(NL) was $1 \%(\mathrm{w} / \mathrm{w})$ and $1 \%(\mathrm{v} / \mathrm{w})$, respectively. Experiment had three replications with randomized block design and $24 \mathrm{~m} \times 6 \mathrm{~m}$ in plot size, planted with $100 \mathrm{Ba}$ kich plants per treatment.

\section{Statistical analysis}

Treatment effects were assessed by analysis of variance (ANOVA) using IRRISTAT for Windows version 5.0 (Biometric Unit, International Rice Research Institute). Mean separation was performed using the least significant difference (LSD) at $P=0.05$ and $P=0.01$ whenever a significant ANOVA $(P<0.05)$ result occurred.

\section{Results}

\section{Effect of MICROTECH-1(NL) on growth of F. proliferatum} in vitro condition

In dual-culture assay, the bio-products significantly suppressed the growth of BKVN, BKDT, and BKPL isolates by at least $52 \%$, and the highest values were obtained with MICROTECH-1(NL). The application of MICROTECH-1(NL) inhibited the mycelial growth of BKVN, BKDT, and BKPL isolates by 70.38, 71.80, and $72.04 \%$, respectively. Except for Actino Vate, Bionite, Ketomium, and BIMA that entailed the low growth inhibition (lower than 60\%), TRICHO and SH-BV1 had also significantly suppressed mycelial growth of BKVN, BKDT, and BKPL isolates. The inhibition percentage for TRICHO and SH-BV1 ranged from $60.90 \%$ with BKPL isolate to $62.09 \%$ with BKVN isolate, and from $66.35 \%$ with BKVN isolate to $67.30 \%$ with BKDT isolate, respectively (Fig. 1).

\section{Effect of MICROTECH-1(NL) on disease severity of FRRBK in pot condition}

Treatment of bio-products 1 week before inoculation with FP significantly reduced disease severity compared to inoculated-untreated control (Fig. 2). Among the tested bio-products, SHBV1 and MICROTECH-1(NL) showed highest suppression of disease severity. The results indicated that in treatment of SH-BV1, disease severity ranged from $7.77 \%$ with BKDT isolate to $9.25 \%$ with BKVN isolate. In treatment of MICROTECH-1(NL), disease severity ranged from $5.92 \%$ with BKDT isolate to $6.66 \%$ with BKPL isolate. In other treatments, disease severity ranged from $9.62 \%$ for Actino Vate with BKDT isolate to $22.96 \%$ for Ketomium with BKPL isolate.

The decrease of disease severity when bio-products were applied simultaneously with inoculation of FP spores showed similar trends, although the disease severity was higher compared to that when bio-products were applied 1 week before inoculation with FP. Disease severity in treatments of SH-BV1 and MICROTECH$1(\mathrm{NL})$ was statistically differentiated compared to other treatments and inoculated-untreated control. With the exception for Ketomium, the disease severity was about $30 \%$ in all of three isolates; the disease severity from all bio-products ranged from 10.37 for MICROTECH-1(NL) with BKVN isolate to $27.78 \%$ for Bionite with BKVN isolate (Additional file 1). Treatment of bio-products 1 week after the inoculation with FP did not reduce disease severity as compared to inoculated-untreated control. Disease severity was more than $43 \%$ and it reached $65.56 \%$ for Ketomium with BKVN isolate (Additional file 2).

\section{Effect of MICROTECH-1(NL) on microorganisms in the soil} The results showed that when Ba kich plants were pretreated with both of SH-BV1 and MICROTECH-1(NL), there was significantly reduced disease severity in comparison to other treatments. The disease severity of this treatment was $11.78 \%$, which is significantly lower than untreated control (80\%). The disease severity in 
treatments with MICROTECH-1(NL) or SH-BV1 for both of Ba kich plants in nursery and pot soils was 15.56 and $19.33 \%$, respectively. On the contrary, treatments were single application of either SH-BV1 or MICROTECH-1(NL) for Ba kich in the nursery or field soil; the disease severity was more than $22.22 \%$. The results showed that Ba kich plants in the nursery were healthier than the control; however, since the pathogen population was high in the field soil and if the field soil was not pretreated before planting, the seedlings were severely prone to pathogen attack (Fig. 3). Therefore, soil treatment was the apex priority for effective management of FRRBK.

$\mathrm{FP}$ population in roots in treatments $\mathrm{SHn}+\mathrm{Cp}$ and $\mathrm{MIn}+\mathrm{Cp}$ was lower compared to control $(\mathrm{Cn}+\mathrm{Cp})$; these two treatments decreased FP population density by 48.00 and $52.89 \%$, respectively. FP population in treatments of $\mathrm{Cn}+\mathrm{SHp}, \mathrm{SHn}+\mathrm{SHp}, \mathrm{Cn}+\mathrm{MIp}, \mathrm{MIn}+\mathrm{MIp}$, and SHnp + MInp was significantly lower as compared to control $(\mathrm{Cn}+\mathrm{Cp})$. In five treatments, the FP population density decreased by $69.63,80.67,81.19,84.52$, and $93.26 \%$, respectively. FP population in roots in treatment of $\mathrm{Cn}+$ MIp was highly decreased compared with MIn $+\mathrm{Cp}$ (81.19\% compared with $52.89 \%)$. FP population in roots in treatment of $\mathrm{Cn}+\mathrm{SHp}$ and $\mathrm{SHp}+\mathrm{Cp}$ showed a similar trend (69.63\% compared with $48.00 \%)$. These results indicated that nursery and pot application, double application of SH-BV1, and MICROTECH-1(NL) significantly decreased FP population in rhizoplane of Ba kich (Fig. 4).
A significant decrease of FP population was detected in rhizoplane soil in treatments $\mathrm{Cn}+\mathrm{SHp}, \mathrm{SHn}+\mathrm{SHp}$, $\mathrm{Cn}+$ MIp, MIn + MIp, and SHnp + MInp as compared to control $(\mathrm{Cn}+\mathrm{Cp})$, resulting in 80.37, 83.26, 80.99, 84.71, and $88.01 \%$ decrease, respectively. Nursery-only application with either SH-BV1 or MICROTECH-1(NL) also decreased the population of FP in rhizoplane soil resulting in 53.09 and $55.98 \%$ decrease compared to control $(\mathrm{Cn}+\mathrm{Cp})$ (Fig. 5).

The FP population in the rhizosphere soil also showed a similar trend. FP population in treatments $\mathrm{Cn}+\mathrm{SHp}$, $\mathrm{SHn}+\mathrm{SHp}, \mathrm{Cn}+\mathrm{MIp}, \mathrm{MIn}+\mathrm{MIp}$, and SHnp+MInp was significant lower as compared to control $(\mathrm{Cn}+\mathrm{Cp})$. In these five treatments, the FP population decreased by $83.55,86.84,87.34,92.96$, and $95.39 \%$, respectively. Meanwhile, FP population in nursery-only treatment of SH-BV1 $(\mathrm{SHn}+\mathrm{Cn})$ or MICROTECH-1(NL) $(\mathrm{MIn}+\mathrm{Cp})$ was lower as compared to control, but significantly higher from that of pot-only treatments $(\mathrm{Cn}+\mathrm{SHp}$ and $\mathrm{Cn}+\mathrm{MIp})$ or double application with either SH-BV1 or MICROTECH1(NL) (SHn + SHp, MIn + MIp, and SHnp + MInp) (Fig. 6).

Total fungal count in rhizoplane soils of treatments $\mathrm{Cn}+\mathrm{SHp}, \quad \mathrm{SHn}+\mathrm{SHp}, \quad \mathrm{Cn}+\mathrm{MIp}, \quad \mathrm{MIn}+\mathrm{MIp}, \quad$ and SHnp + MInp decreased by 57.91, 67.35, 61.87, 72.08, and $79.19 \%$, respectively, as compared to that of control. Total bacterial count in the rhizoplane soils of the above treatments increased by $80.37,82.99,77.7,83.44$, and $88.59 \%$, respectively, as compared to that of control.

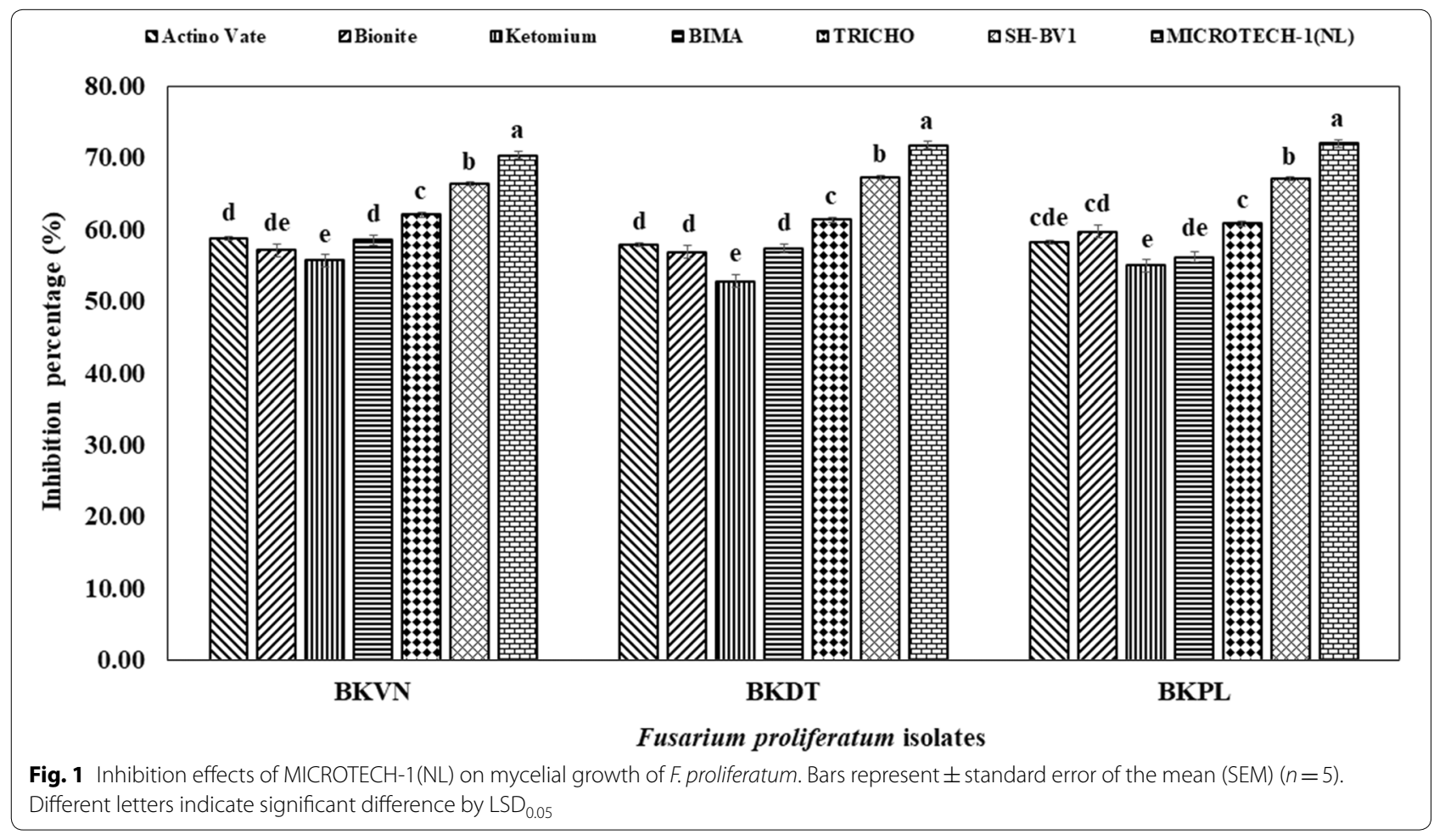




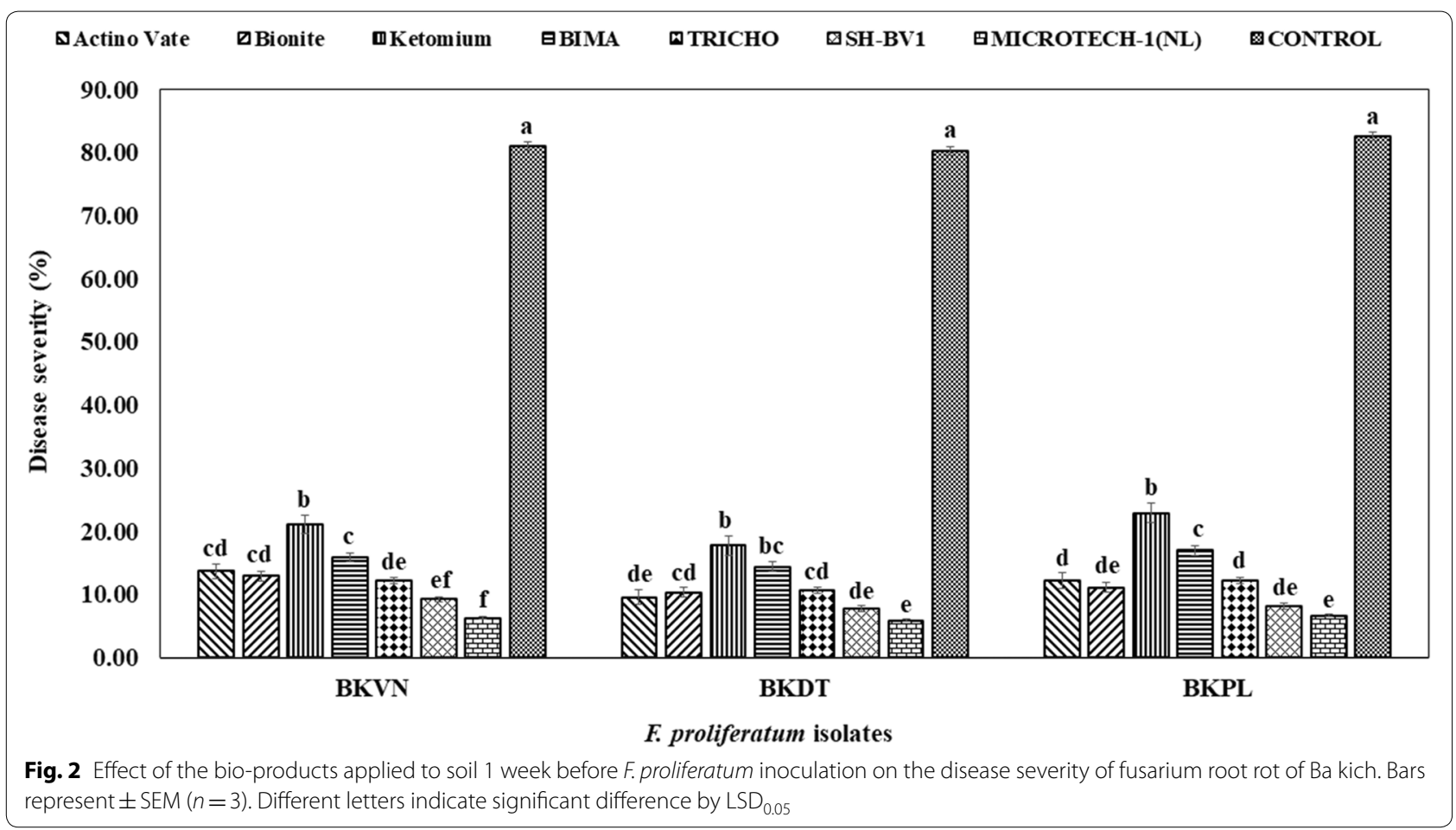

The total actinobacteria count in the rhizoplane soil also increased and resulted in $64.22,68.85,65.47,74.17$, and $77.73 \%$, respectively, compared to that of control. In addition, double application of either SH-BV1 or MICROTECH-1(NL) increased total bacteria and actinobacteria count in comparison to nursery-only applications ( $\mathrm{SHn}+\mathrm{Cp}$ and MIn $+\mathrm{Cp}$ ) (Additional file 3).

The changes in microbial count in the rhizosphere soil showed similar trends, although the values were lower than those in the rhizoplane soils. Total fungal count in the rhizosphere soil of the treatments $\mathrm{Cn}+\mathrm{SHp}, \mathrm{SHn}+\mathrm{SHp}$, $\mathrm{Cn}+\mathrm{MIp}, \mathrm{MIn}+\mathrm{MIp}$, and SHnp + MInp decreased by $58.09,68.15,62.79,73.47$, and $80.93 \%$, respectively, compared to that of control. The total bacterial count in the rhizosphere soil of the above treatments increased by $44.61,73.06,58.73,74.40$, and $81.42 \%$, respectively, as compared to that of control. The total actinobacteria count in the rhizosphere soil also increased and resulted in $64.22,61.74,70.27,63.05,74.75$, and $87.17 \%$, respectively, as compared to that of control (Additional file 4).

\section{Effect of MICROTECH-1(NL) on disease severity of FRRBK in the field conditions}

Double application of SH-BV1 and MICROTECH-1(NL) both in the nursery and in the field significantly decreased disease severity as compared to single nursery application or field application and in comparison to respective controls in Vo Nhai, Dai Tu, and Phu Luong districts. Disease severity in treatments SHnf + MInf, MIn + MIf, SHn + MIf,
SHn + SHf, and MIn + SHf were significantly decreased by $90.47,87.10,84.16,79.33$, and 78.01\%, respectively, as compared to control $(\mathrm{Cn}+\mathrm{Cp})$. The disease severity in nurseryonly treatments $\mathrm{MIn}+\mathrm{Cf}$ and $\mathrm{SHn}+\mathrm{Cf}$ was decreased by 40.32 and $39.15 \%$, respectively, as compared to control. Whereas, those in field-only treatments $\mathrm{Cn}+$ MIf and $\mathrm{Cn}+\mathrm{SHf}$ resulted in 73.02 and $70.09 \%$ decrease compared with control, respectively. The decrease in disease severity in Dai Tu and Phu Luong districts showed similar trends. These data indicate that double application of SH-BV1 and MICROTECH-1(NL) in nursery and in the field leads to low disease severity of FRRBK (Fig. 7).

\section{Discussion}

Mounting disease pressure in high value crops requires frequent and sometimes injudicious applications of hazardous pesticides, impacting both human and environmental health. Thus, the search for ecologically safer, cost effective, and sustainable alternative for the effective management of fusarium root rot is a top priority in Viet Nam [34, 35].

In the present study, various bio-products were tested for their effectiveness against FP and FRRBK in in vitro, pot, and in the field conditions. Previous reports indicated that different antagonistic microorganism inhibit the growth of Fusarium spp. that are the causal pathogens of different diseases $[7,8,16,17]$. The introduction of MICROTECH-1(NL) into culture medium significantly suppressed the mycelial growth of FP isolates by 70.38 $72.04 \%$ higher than that from other tested bio-products 


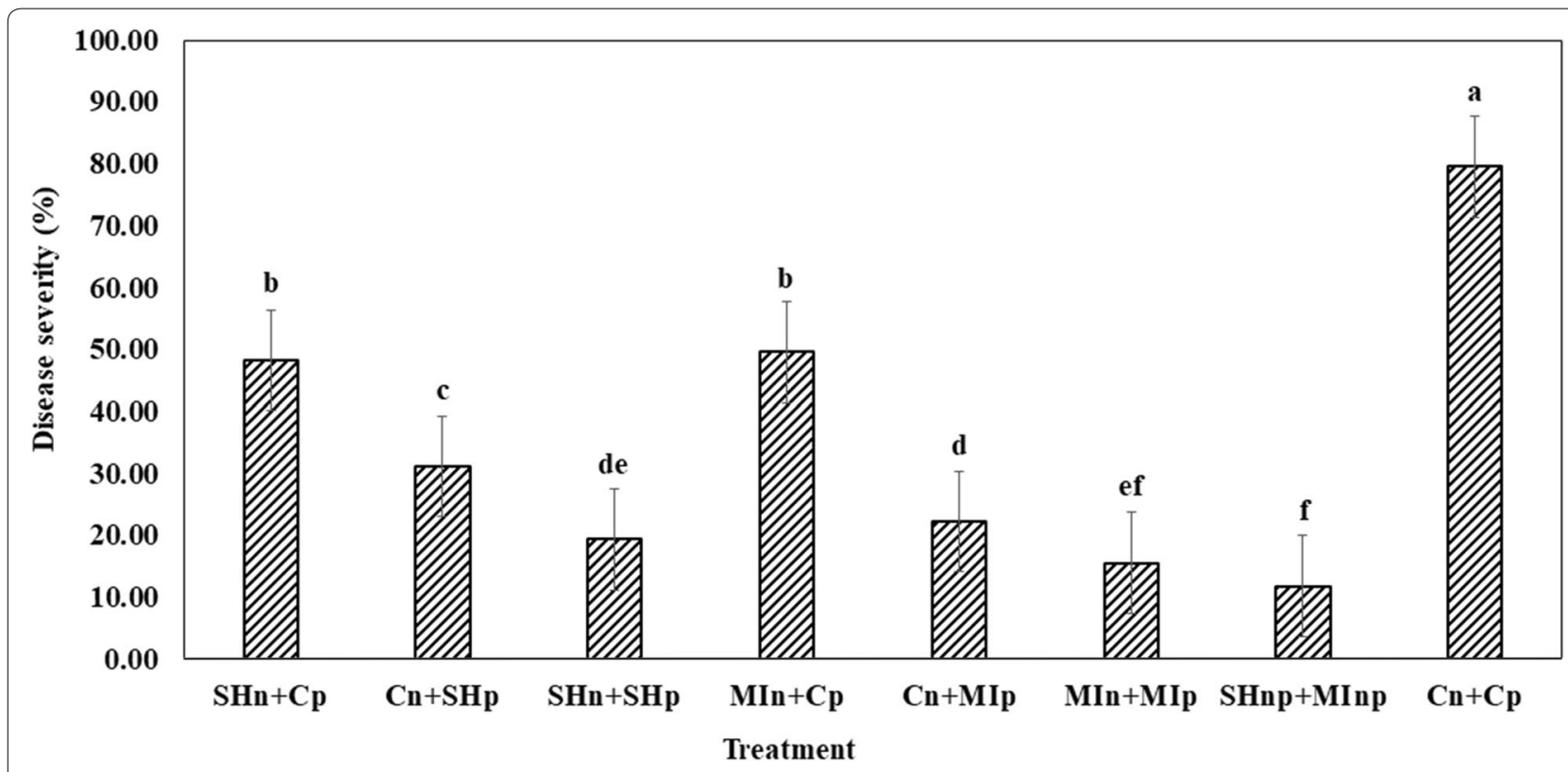

Fig. 3 Effect of MICROTECH-1(NL) on disease severity of FRRBK under nursery and pot conditions. Bars represent \pm SEM $(n=3)$. Different letters indicate significant difference by $\mathrm{LSD}_{0.05}$

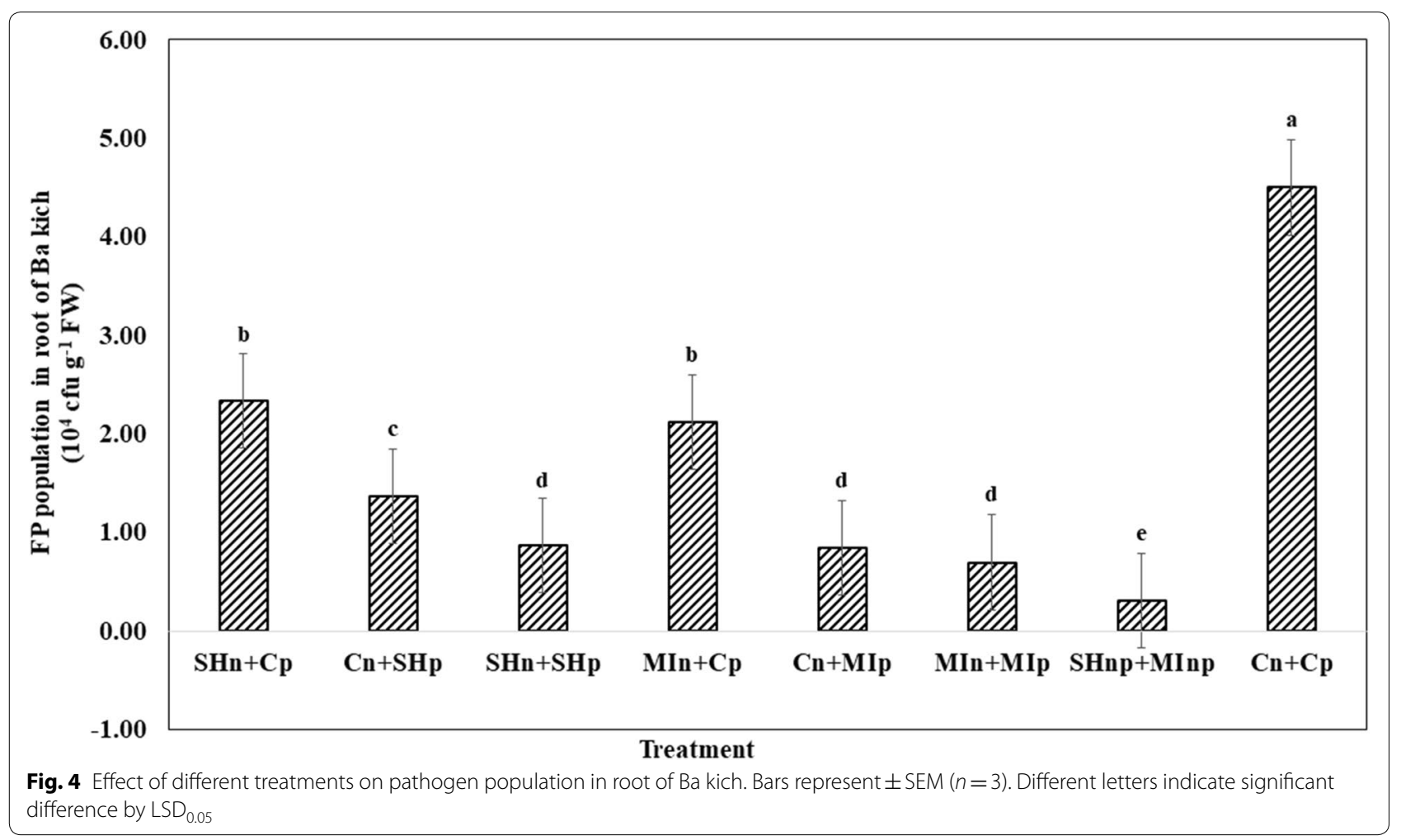

(52.84\% for Ketomium to $67.30 \%$ for SH-BV1) (Fig. 1). This suggests that the diversity of consortia of antagonistic microorganism species in MICROTECH-1(NL) resulting in higher inhibition percentage compared with that produced by consortia of species in SH-BV1 and other bio-products composed by single species or less diversity of antagonistic microorganisms. One of the biggest challenges of production of bio-products composed from different antagonistic microorganism is the compatibility of all the species. In our case, they were separately 

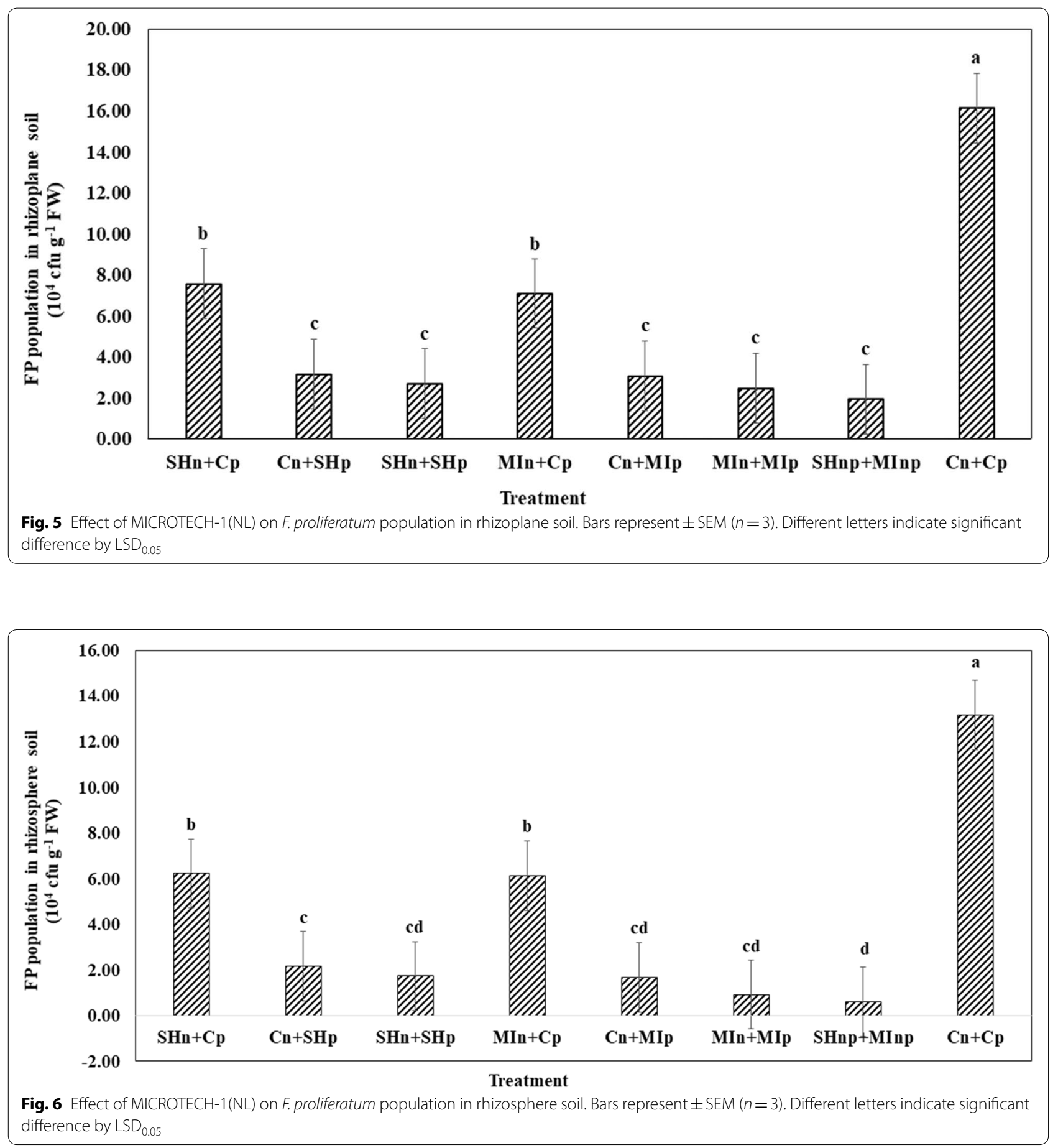

cultured in different media before composed into an environment with the same ratio. The efficacy of MICROTECH-1(NL) was tested every 2 months after composing until 12 months. The results indicated that its efficacy was unaltered during storage at room temperature (data not shown) suggesting that the consortia of antagonistic microorganisms in MICROTECH-1(NL) are compatible.
Addition of the tested bio-products before or simultaneous inoculation with pathogen significantly reduced the disease severity of FRRBK. The disease severity reduction was greater when bio-products were applied into the soil 1 week before inoculation with FP. The disease severity ranged from $5.92 \%$ (for MICROTECH$1(\mathrm{NL})$ with BKDT isolate) to $22.96 \%$ (for Ketomium with 
BKPL isolate) as compared to inoculated-untreated control, in which disease severity ranged 80.37 to $82.59 \%$, respectively. Specially, MICROTECH-1(NL) highly suppressed the development of FRRBK resulting up to 92.6\% of disease severity reduction as compared to inoculateduntreated control (Fig. 2). Simultaneous application of bio-products and FP spores also significantly reduced the disease severity resulting in 60.3 to $86.2 \%$ as compared to inoculated-untreated control. Among them, MICROTECH-1(NL) also showed highest efficacy in comparison with other bio-products (Additional file 1). However, applying these bio-products 1 week after inoculation with pathogen reduced disease severity, but the reduction was not exceeding $46 \%$ (Additional file 2), suggesting that the aforementioned bio-products need to be applied into field soil before transplantation. Previous studies showed that pre-treatment of soil with antagonistic microorganisms such as T. harzianum, Pythium oligandrum, B. subtilis, B. pumilus, etc., induces systemic responses in host plants [36-39], triggers various defense mechanisms such as accumulation of pathogenesis related (PR) proteins, deposition of structural barriers [40], and accumulation of antimicrobial phenolics [41], and stimulates plant resistance/tolerance $[37,42,43]$ that protects plants against soil-borne diseases [44, 45].

In addition, double application of MICROTECH-1(NL) into both the nursery and the pot soils, significantly reduced disease severity (Fig. 3), suppressed FP population in root of Ba kich (Fig. 4), in rhizoplane soil (Fig. 5), and in rhizosphere soil (Fig. 6); increased total bacteria and actinobacteria count in rhizoplane and rhizosphere soils (Additional files 3,4) and effectively increased the growth of $\mathrm{Ba}$ kich compared to single application and non-treatment control (data not shown). Suggesting that MICROTECH-1(NL) has a broad spectrum of effects on FP and FRRBK, improves the antagonistic microorganisms' population in the soil, improves soils quality, suppresses the growth of FP in the rhizoplane and rhizosphere, and protects the Ba kich plant from the pathogen attack. Similar results were obtained in the field condition, double use of MICROTECH-1(NL) into both nursery and field soils highly reduced disease severity of FRRBK in comparison to single use in nursery or field soil (Fig. 7). These results are relatively consistent with previous studies showing the effect of antagonistic microorganisms in reducing the incidence of different Fusarium diseases [5, 16-19, 30, 46-49]. They act against pathogens by synthesizing antimicrobial secondary metabolites $[13,15,20,26,28,31]$, induce systemic resistant in plants $[7,8,16,17,26,27]$, inhibit the growth of pathogens, and suppress disease incidence and severity $[5,8-11,13,14$, $16,18,19,21-24,30,32]$.

The growth of Ba kich plants in pot and in the field conditions on application of MICROTECH-1(NL) was higher than that of untreated control (data not shown). This suggests that certain antagonistic strains of MICROTECH-1(NL) colonize the soil, root surfaces of the plants to the same extent as the phytopathogens [50], or secrete

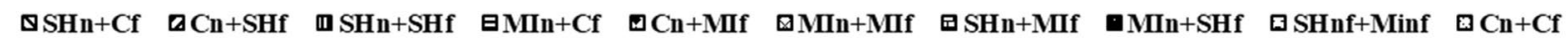

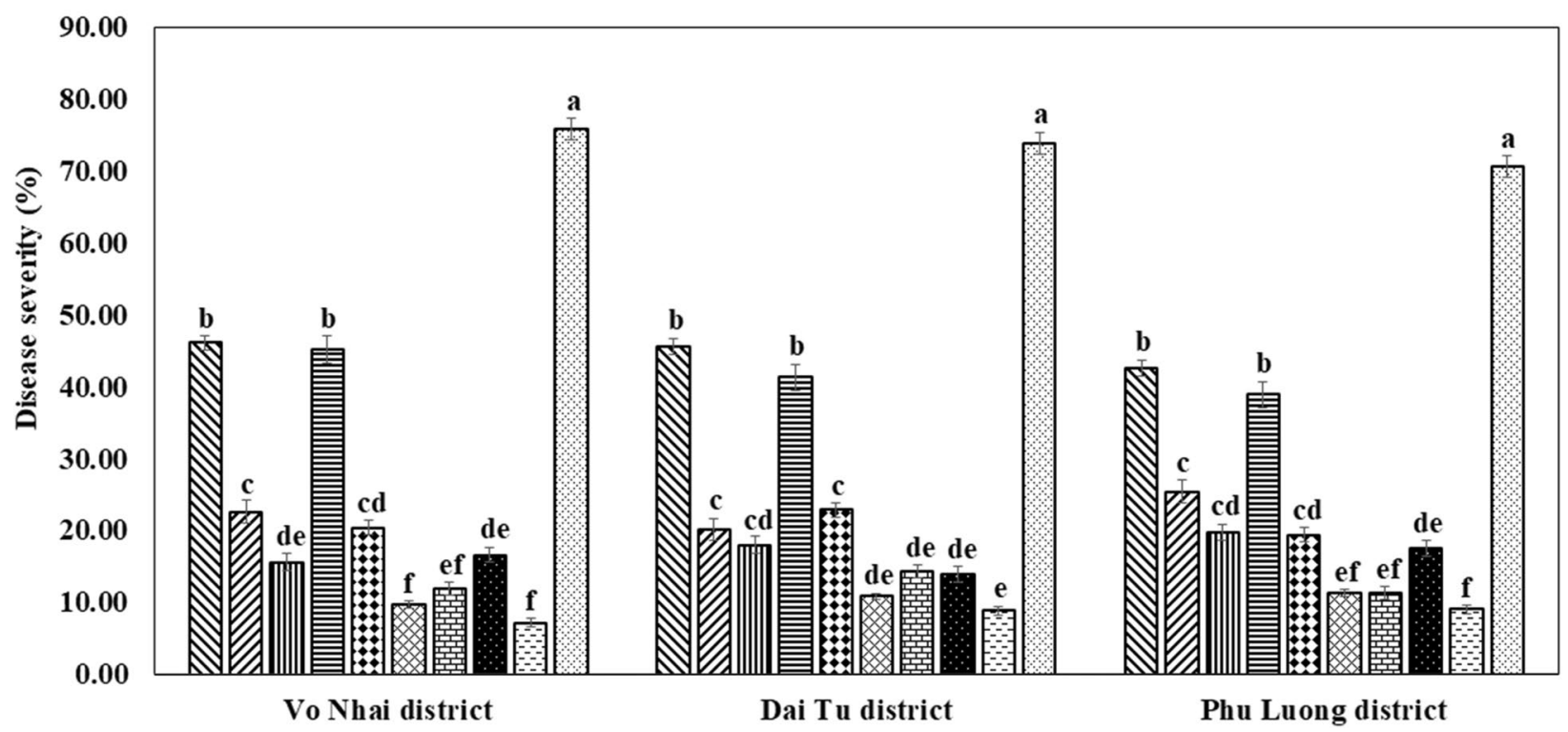

Fig. 7 Effect of MICROTECH-1(NL) on disease severity of FRRBK under the field condition. Bars represent \pm SEM $(n=3)$. Different letters indicate significant difference by $L S D_{0.05}$ 
considerable amounts of biologically active substances that promote root growth, improve nutrient uptake by the plants [31], and increase plant quality $[2,25]$.

\section{Conclusion}

The results in this study demonstrated that MICROTECH-1(NL) containing a consortium of compatible agriculturally important microorganisms with varied biological functions proved as an effective tool for sustainable management of fusarium root rot of Ba kich. For Ba kich plants in the nursery, spraying MICROTECH-1(NL) (1\%) 2-3 times per year and in field conditions, pre-treatment of field soils with MICROTECH-1(NL) (1\%) 1-2 weeks before planting; and after planting in the field, applying of MICROTECH-1(NL) (1\%) 2-3 times per year are highly recommended. Though determination of the precise mode of action of MICROTECH-1(NL) is still required.

\section{Supplementary information}

Supplementary information accompanies this paper at https://doi. org/10.1186/s40538-019-0168-x.

Additional file 1. Effect of application of bio-products at the same time with F. proliferatum on the disease severity of fusarium root rot of Ba kich.

Additional file 2. Effect of application of bio-products 1 week after inoculation with F. proliferatum on the disease severity of fusarium root rot of Ba kich.

Additional file 3. Effects of application of MICROTECH-1 ${ }^{(\mathrm{NL})}$ on microorganism density in rhizoplane soil (cfu g ${ }^{-1}$ soil).

Additional file 4. Effects of application of MICTROTECH-1 ${ }^{\text {(NL) }}$ on microorganism density in rhizosphere soil ( $\mathrm{cfu} \mathrm{g}^{-1}$ soil).

\section{Abbreviations}

FRRBK: fusarium root rot of Ba kich:; FP: Fusarium proliferatum; LSD: least significant difference.

\section{Acknowledgements}

The authors are grateful to the Ministry of Education and Training of Viet Nam for providing financial support through Grant Number: B2018-TNA-59.

\section{Authors' contributions}

PVT and TXH conceived the idea, and planned the experiments. DTN, NCH, $\mathrm{NVH}$, and HTBT conducted the experiments, analyzed the data, and prepared the draft of the manuscript. PVT, TXH, and CK revised and edited the manuscript. All authors read and approved the final manuscript.

\section{Funding}

This work was conducted as a part of research project funded by the Ministry of Education and Training of Viet Nam [Grant Number: B2018-TNA-59].

\section{Availability of data and materials}

Data will be made available on request.

\section{Ethics approval and consent to participate}

Not applicable.

\section{Consent for publication}

All authors have provided their consent for submission of the manuscript to CBTA.

\section{Competing interests}

The authors declare that they have no competing interests.

\section{Author details}

${ }^{1}$ Faculty of Agriculture, Thai Nguyen University of Agriculture and Forestry, Quyet Thang, Thai Nguyen City, Thai Nguyen Province, Viet Nam. ${ }^{2}$ Department of Biochemistry, Institute of Science, Banaras Hindu University, Varanasi 221005 , India. ${ }^{3}$ Viet Nam Academy of Agricultural Sciences, Vinh Quynh, Thanh Tri District, Ha Noi City, Viet Nam. ${ }^{4}$ Plant Protection Research Institute of Viet Nam, Duc Thang, Bac Tu Liem District, Ha Noi City, Viet Nam.

Received: 28 May 2019 Accepted: 24 October 2019

Published online: 15 November 2019

\section{References}

1. Nguyen DT, Hieu NC, Thao HTB, Hoat TX. Molecular characterization of Fusarium proliferatum associated with root rot disease of Indian mulberry (Morinda officinalis How.) in Viet Nam. Arch Phytopathol Plant Protect. 2019;52(1-2):200-17. https://doi.org/10.1080/03235408.2019.1603351.

2. Haas D, Défago G. Biological control of soil-borne pathogens by fluorescent pseudomonads. Nat Rev Microbiol. 2005;3:307-19.

3. Siddiqui ZA. PGPR: prospective biocontrol agents of plant pathogens. In: Siddiqui ZA, editor. PGPR: biocontrol and biofertilization. Netherlands: Springer; 2006. p. 111-42.

4. Kloepper JW, Leong J, Teintze M, Schroth MN. Enhanced plant growth by siderophores produced by plant growth-promoting rhizobacteria. Nature. 1980;286:885-6.

5. Sivamani E, Gnanamanickam SS. Biological control of Fusarium oxysporum f. sp. cubense in banana by inoculation with Pseudomonas fluorescens. Plant Soil. 1988;107:3-9.

6. Hibar K, Daami-Remadi M, Hamada W, El-Mahjoub M. Bio-fungicides as an alternative for tomato Fusarium crown and root rot control. Tunis J Plant Protect. 2006;1:19-29.

7. Cavaglieri L, Orlando J, Rodríguez MI, Chulze S, Etcheverry M. Biocontrol of Bacillus subtilis against Fusarium verticillioides in vitro and at the maize root level. Res Microbiol. 2005; 156:748-54.

8. Cao Y, Zhang Z, Ling N, Yuan Y, Zheng X, Shen B, Shen Q. Bacillus subtilis SQR 9 can control Fusarium wilt in cucumber by colonizing plant roots. Biol Fert Soils. 2011;47:495-506.

9. Lugtenberg BJ, Kravchenko JLV, Simons M. Tomato seed and root exudate sugars: composition, utilization by Pseudomonas biocontrol strains and role in rhizosphere colonization. Environ Microbiol. 1999;1:439-46.

10. Achouak W, Conrod S, Cohen V, Heulin T. Phenotypic variation of Pseudomonas brassicacearum as a plant root colonization strategy. Mol Plant Microbe Interact. 2004;17:872-9.

11. Validov SZ, Kamilova F, Lugtenberg BJJ. Pseudomonas putida strain PCL1760 controls tomato foot and root rot in stonewool under industrial conditions in a certified greenhouse. Biol Control. 2009;48:6-11.

12. Karthikeyan M, Radhika K, Mathiyazhagan S, Bhaskaran R, Samiyappan $R$, Velazhahan R. Induction of phenolics and defense-related enzymes in coconut (Cocos nucifera L.) roots treated with biological agents. Braz J Plant Physiol. 2006;18(3):367-77.

13. Erdogan $\mathrm{O}$, Benlioglu K. Biological control of Verticillium wilt on cotton by the use of fluorescent Pseudomonas spp. under field conditions. Biol Control. 2010;53:39-45.

14. Van Loon LC, Bakker PAHM, Pieterse CMJ. Systemic resistance induced by rhizosphere bacteria. Annu Rev Phytopathol. 1998;36:453-83.

15. Bubici G. Streptomyces spp as biocontrol agents against Fusarium species. CAB Reviews. 2018;13:050. https://doi.org/10.1079/pavsnnr201813050.

16. Faheem M, Raza W, Zhong W, Nan Z, Shen QR, Xu YC. Evaluation of the biocontrol potential of Streptomyces goshikiensis YCXU against Fusarium oxysporum f sp niveum. Biol Control. 2015;81:101-10.

17. Kawuri R, Suprapta DN, Nitta Y. Antagonistic activity of Streptomyces thermocarboxydus to Fusarium oxysporum: the cause of leaf rot disease on Aloe vera (Aloe barbadensis Mill) in Bali, Indonesia. Malays J Microbiol. 2018;14:10-5.

18. Wang SM, Liang $Y$, Shen $T$, Yang $H$, Shen BA. Biological characteristics of Streptomyces albospinus CT205 and its biocontrol potential against cucumber Fusarium wilt. Biocontrol Sci Techn. 2016;26:951-63. 
19. Rashad YM, Al-Askar AA, Ghoneem KM, Saber WIA, Hafez EE. Chitinolytic Streptomyces griseorubens E44G enhances the biocontrol efficacy against Fusarium wilt disease of tomato. Phytoparasitica. 2017;45:227-37.

20. Oyetayo VO, Adetuyi FC, Akinyosoye FA. Safety and protective effect of Lactobacillus acidophilus and Lactobacillus casei used in as probiotic agent in vivo. Afr J Biotechnol. 2003;2:448-52.

21. Jay JM, Loessner MJ, Golden DA. Modern food microbiology. 7th ed. New York: Springer; 2006.

22. Roselló G, Bonaterra A, Francés J, Montesinos L, Badosa E, Montesinos E. Biological control of fire blight of apple and pear with antagonistic Lactobacillus plantarum. Eur J Plant Pathol. 2013;137:621-33.

23. Omodamiro RM, Ojimelukwe PC, Asiedu R. In vitro inhibition of Fusarium by lactic acid bacteria ( $L A B)$ : implication of yam disease control for economic growth in Nigeria. Br J Appl Sci Technol. 2015:5:409-16.

24. Roselló G, Francés J, Daranas N, Montesinos E, Bonaterra A. Control of fire blight of pear trees with mixed inocula of two Lactobacillus plantarum strains and lactic acid. J Plant Pathol. 2017;99:111-20.

25. Koh RH, Song HG. Effects of application of Rhodopseudomonas sp. on seed germination and growth of tomato under axenic conditions. J Microbiol Biotechnol. 2007;17:1805-10.

26. Vleesschauwer DD, Höfte M. Rhizobacteria-induced systemic resistance. In: Van Loon LC, editor. Advances in botanical research. UK: Elsevier; 2009. p. 223-81.

27. Su P, Tan X, Li C, Zhang D, Cheng J, Zhang S, Zhou S, Yan Q, Peng J, Zhang Z, Liu Y, Lu X. Photosynthetic bacterium Rhodopseudomonas palustris GJ-22 induces systemic resistance against viruses. Microb Biotechnol. 2017;10:612-24.

28. Reed G, Nagodawithana TW. Yeast technology. 2nd ed. New York: Van Nostrand Reinhold; 1991.

29. Natio K, Nagamo S, Fury K, Suzk H. Effect of benzyladenine on RNA and protein synthesis in intact bean leaves at various stages of ageing. Plant Physiol. 1981;52:342-8.

30. Shalaby ME, El-Nady MF. Application of Saccharomyces cerevisiae as a biocontrol agent against Fusarium infection of sugar beet plants. Acta Biol Szeged. 2008;52:271-5.

31. Narula N, Guptha KG. Ammonia excretion by Azotobacter in liquid culture and soil in the presence of manganese and clay minerals. Plant Soil. 1986:93:205-9.

32. Swapna K, Tamil V, Mahadevaswamy A, Aswathanarayana DS, Gundappago RC. Biocontrol mechanisms of efficient Azotobacter isolates against Fusarium solani causing Fusarium wilt of Chilli (Capsicum annum L.) under in vitro conditions. Int J Curr Microbiol Appl Sci. 2018;7:2696-702.

33. Zhao Q, Dong C, Yang X, Mei X, Ran W, Shen Q, Xu Y. Biocontrol of Fusarium wilt disease for Cucumis melo melon using bio-organic fertilizer. App Soi Ecol. 2011:47:67-75

34. Keswani C, Sarma BK, Singh HB. Synthesis of policy support, quality control, and regulatory management of biopesticides in sustainable agriculture. In: Singh H, Sarma B, Keswani C, editors. Agriculturally Important Microorganisms. Singapore: Springer; 2016. p. 3-12.

35. Toan PV. Biofertilizer Research, Development, and Application in Vietnam. In: Singh H, Sarma B, Keswani C, editors. Agriculturally Important Microorganisms. Singapore: Springer; 2016. p. 197-217.

36. Mohammadi M, Kazemi H. Changes in peroxidase and polyphenoloxidase activities in susceptible and resistant wheat heads inoculated with Fusarium graminearum and induced resistance. Plant Sci. 2002;162:491-8.

37. Pozo MJ, Cordier G, Dumas-Gaudot E, Gianinazzi S, Bare JM, Azcon-Agui$\operatorname{lar}$ G. Localized versus systemic effect of arbuscular mycorrhizal fungi on defense responses to Phytophthora infection in tomato plant. J Exp Bot. 2002:53:525-34.
38. Thangavelu R, Palaniswami A, Doraiswamy S, Vvelazhahan R. The effect of Pseudomonas fluorescens and Fusarium oxysporum f. sp. cubense on induction of defence enzymes and phenolics in banana. Biol Plantarum. 2003;46:107-12.

39. Falahian F, Oraghi AZ, Fahimi H. Effect of mycorrhizal fungi on some defence enzymes against Gaeumannomyces graminis in wheat. Pak J Biol Sci. 2007;10:2257-66.

40. Benhamou N, Kloepper JW, Quadt-Hallman A, Tuzun S. Induction of defense related ultrastructural modifications in pea root tissues inoculated with endophytic bacteria. Plant Physiol. 1996;112:919-29.

41. Keswani C. Proteomics studies of thermotolerant strain of Trichoderma spp. Ph.D. thesis, Banaras Hindu University, Varanasi, India (2015).

42. Vázquez MM, César S, Azcón R, Barea JM. Interactions between arbuscular mycorrhizal fungi and other microbial inoculants (Azospirillum, Pseudomonas, Trichoderma) and their effects on microbial population and enzyme activities in the rhizosphere of maize plants. Appl Soil Ecol. 2000;15:261-72.

43. Srivastava R, Khalid A, Singh US, Sharma AK. Evaluation of arbuscular mycorrhizal fungus, fluorescent Pseudomonas and Trichoderma harzianum formulation against Fusarium oxysporum f. sp. lycopersici for the management of tomato wilt. Biol Control. 2010;53:24-31.

44. Raupach GS, Liu L, Murphy JF, Tuzun S, Kloepper JW. Induced resistance in cucumber and tomato against cucumber mosaic virus using plant growth promoting rhizobacteria. Plant Dis. 1996;80:891-4.

45. Bisen K, Keswani C, Patel JS, Sarma BK, Singh HB. Trichoderma spp.: efficient inducers of systemic resistance in plants. In: Choudhary D, Varma A, editors. Microbial-mediated induced systemic resistance in plants. Singapore: Springer; 2016. p. 185-95.

46. Mishra S, Singh A, Keswani C, Saxena A, Sarma BK, Singh HB. Harnessing plant-microbe interactions for enhanced protection against phytopathogens. In: Arora N, editor. Plant microbes symbiosis: applied facets. Springer: New Delhi; 2015. p. 111-25.

47. Singh HB, Sarma BK, Keswani C. Agriculturally important microorganisms: commercialization and regulatory issues in Asia. Singpore: Springer; 2016.

48. Singh HB, Sarma BK, Keswani C. Advances in PGPR research. Oxford: CAB International; 2017.

49. Chung S, Kong H, Buyer JS, Lakshman DK, Lydon J, Kim SD, Roberts DP. Isolation and partial characterization of Bacillus subtilis ME488 for suppression of soilborne pathogens of cucumber and pepper. Appl Microbiol Biotechnol. 2008;80:115-23.

50. Whipps JM. Microbial interactions and biocontrol in the rhizosphere. J Exp Bot. 2001;52:487.

\section{Publisher's Note}

Springer Nature remains neutral with regard to jurisdictional claims in published maps and institutional affiliations.

\section{Submit your manuscript to a SpringerOpen ${ }^{\circ}$ journal and benefit from:}

- Convenient online submission

- Rigorous peer review

- Open access: articles freely available online

- High visibility within the field

- Retaining the copyright to your article

Submit your next manuscript at springeropen.com 